\title{
Neotropical tadpoles: spatial and temporal distribution and habitat use in a seasonal lake in Veracruz, México
}

\author{
Roberto E. Torres-Orozco ${ }^{1}$, Cecilia L. Jimenez-Sierra ${ }^{2}$, Richard C. Vogt ${ }^{3,4}$, and Jose-Luis \\ Villarreal Benitez ${ }^{3}$. \\ ${ }^{1,2}$ Universidad Autonoma Metropolitana-Iztapalapa. Departementos de ${ }^{1}$ Hidrobiologia and ${ }^{2}$ Biologia, Apt Post. 55-535, \\ Mexico. D. F., Mexico. C.P. 09340. \\ 3 Estación de Biología Tropical "Los Tuxtlas". Universidad Nacional Autonoma de Mexico. Apt. Post. 91. San Andres \\ Tuxtla. Veracruz. Mexico C.P. 95700. \\ ${ }^{4}$ Present address: Curador de Répteis e Anfíbios, Coordenação de Pesquisas em Biologia Aquática (CPBA), Instituto \\ Nacional de Pesquisas da Amazônia (INPA), Av. André Araújo 2936, Petrópolis. Caixa Postal 478, Manaus, AM, \\ Brasil, CEP 69083-000. E-mail: vogt@inpa.gov.br.
}

\begin{abstract}
Neotropical tadpoles: spatial and temporal distribution and habitat use in a seasonal lake in Veracruz, México. We studied a tadpole assemblage in a seasonal neotropical lake where 14 species of anurans reproduce. Tadpoles were collected monthly at nine sampling stations at depth intervals of $1 \mathrm{~m}$ from the surface to the bottom $(13 \mathrm{~m})$. Sufficient numbers of tadpoles of three species were collected to compare habitat use. This three species assemblage breed in the following order (first to last): Smilisca baudinii, Gastrophryne usta, and Rana berlandieri. R. berlandieri had the greatest microhabitat breadth followed by S. baudinii. S. baudinii and G. usta had high microhabitat overlap, but significant differences in microhabitat use were found. $S$. baudinii tended to occur near the bottom, while G. usta was near the surface. This study shows that temporal and habitat partitioning both occur and depend on the species of tadpole. Dynamic interactions occur between habitat and temporal dimensions. Phenology and habitat selection depend both on the species and on abiotic and biotic factors.
\end{abstract}

Keywords: Smilisca baudinii, Gastrophryne usta, Rana berlandieri, tadpoles, Anura, habitat use, temporal distribution, Mexico.

\section{Introduction}

Resource partitioning is a fundamental property of complex ecological communities. Habitat, food, and time are three primary categories of resources which may be

Received 18 November 2002

Accepted 30 December 2002 partitioned (Pianka 1975, Toft 1985). In tadpoles the principal resource partitioned is space (Inger et al. 1986) and time (see Toft 1985, for review). The larvae of different species use the available resources in different ways (Heyer 1976). However, resource availability and use may change as the species diversity or individual species densities change. Therefore species interact in dimensions of 
space and time and change in patterns of resource use.

Extensive studies of anuran tadpole resource partitioning have been made in the temperate zone (e.g. Heyer 1979, Morin 1983, Steinwascher 1979) where species richness and diversity are low in comparison to the neotropics and seasonality is based primarily on temperature. The few comparable tropical studies (Gascon 1991, Heyer 1973, 1976, Heyer et al. 1975) were conducted either in small ponds with a strong seasonal effect and limited habitat complexity or were long-term studies with little emphasis on phenology. Recently, several long term excellent studies have been undertaken in the neotropics dealing with habitat and niche partitioning of tadpole assemblages (Wild 1996, Eterovick and Sazima 2000, Eterovick and Fernandes 2001, Eterovick and Barros, in press). Temperate zone studies have shown that the time dimension dominates resource partitioning. This is also true for studies in tropical situations (Toft 1985). However, long-term studies have shown that the primary dimension in tadpole resource partitioning is habitat (Inger et al. 1986). Toft (1985) concluded, on the other hand, that resource partitioning in anuran larvae cannot be explained by one factor but must invoke complex interactions among physical and biological factors such as predation and competition.

We studied an anuran community with moderate diversity, 14 species, in a markedly seasonal tropical habitat (Vogt 1997). The body of water is large, and habitats are heterogeneous both vertically and horizontally. In this community, following the general predictions of Toft (1985), we expected to find interspecies interactions in the dimensions of both time and habitat, which would reveal patterns of resource partitioning. Prior to this study one of us (RCV) had observed a high concentration of tadpoles in the lake, seemingly in all parts and all depths. We undertook this study to discover if in fact all species are found at all depths within the lake or if there is spatial distribution among the tadpoles of different species. In this study we addressed the following questions: (1) when are the tadpoles of each species present in the lake? (2) at what depth are the tadpoles of each species present? and (3) is there an interaction among tadpoles of different species in space and time?

\section{Material and Methods}

\section{Study Area}

Laguna del Zacatal (Figure 1), an ephemeral lake in southeastern Veracruz, Mexico $\left(18^{\circ} 35^{\prime} \mathrm{N}\right.$, $95^{\circ} 06^{\prime} \mathrm{W}$, elevation $170 \mathrm{~m}$ ), lies within the Estación de Biología Tropical Los Tuxtlas, a reserve of tropical evergreen rainforest of 700 ha administered by the Instituto de Biologia of the Universidad Nacional Autonoma de Mexico. Annual mean precipitation is $4,900 \mathrm{~mm}$ and mean annual temperature is $27^{\circ} \mathrm{C}$. The rainy season extends from June through February. Most rain falls between July and November, but in the dry season, March through May, mean precipitation is $111.7 \mathrm{~mm} / \mathrm{month}$.

The bed of Laguna de Zacatal begins to flood from late May to mid-June depending on the timing of the rains when the lake is full it has a surface area of $76,453 \mathrm{~m}^{2}$, a volume of $537,236 \mathrm{~m}^{3}$ and a depth of 2-13 m (TorresOrrozco et al. 1997). Water depth fluctuates several meters throughout the year, and the lake completely dries by April or early May of every year (Figures 1 and 2). Terrestrial vascular plants in the lake bed during the dry season provide food for tadpoles during the subsequent rainy season.

\section{Tadpole Sampling}

Tadpoles were collected monthly (except in December, 1986, when only visual observations were made) from June 1986 to April 1987. On 15 May 1987, when the drying lake was a few centimeters deep, samples were taken to deter- 
mine the fate of the tadpole populations. Tadpoles were collected in unbaited doubleentrance funnel traps constructed of PVC tubing (30 cm long $\times 10 \mathrm{~cm}$ diameter) with funnel entrances of green plastic window screening held in place by rubber bands. The traps were attached at 1-m intervals to an anchored vertical line. Nine sampling stations selected in different parts of the lake were the same for the duration of the study (Figure 1). Traps were located at $1-\mathrm{m}$ intervals from the surface to the bottom (as many as possible depending on the water level). Traps were checked 20 hours after

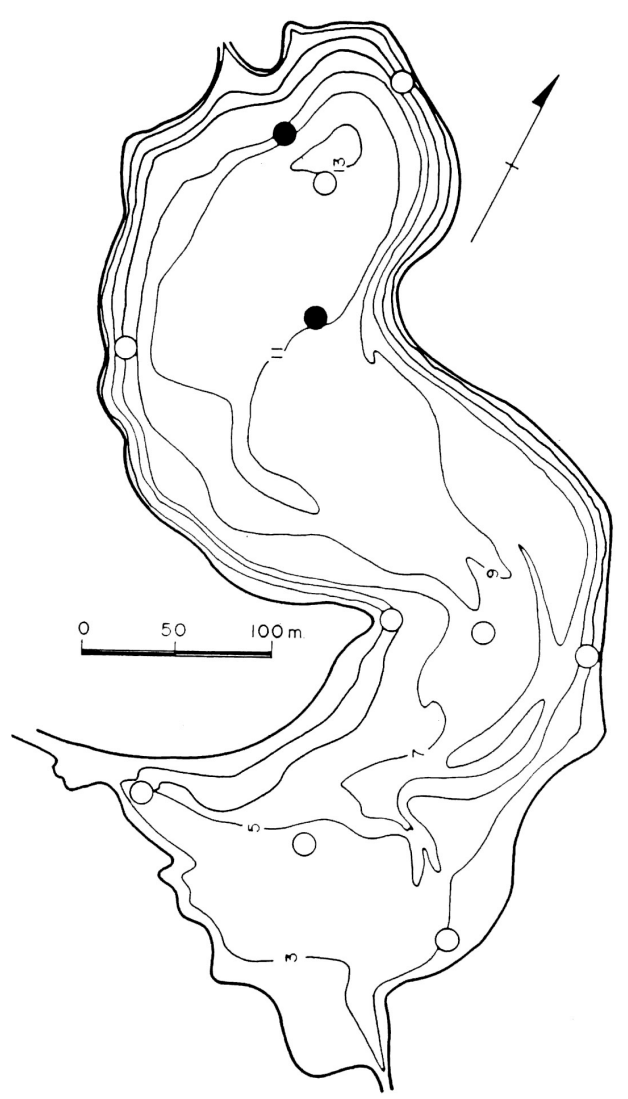

Figure 1 - Bathymetric map of Laguna del Zacatal (from Torres-Orozco et al. 1997) and trapping stations (open circles). Sites marked with black circles were sampled 11-12 April 1987 when the lake was almost dry. installation. This sampling method provided a comparable passive sample at each depth.

All tadpoles were preserved in $15 \%$ neutral buffered formalin, were identified in the laboratory, and the number of individuals of each species found at each depth was recorded. Samples were assigned to one of three microhabitats (surface, water column, bottom) by the following criteria: water depth was $<1$ $m$ only the surface microhabitat was trapped; water depth reached $1 \mathrm{~m}$, surface and bottom were trapped; water depth was $>2 \mathrm{~m}$ all three microhabitats were trapped; water depth was > $4 \mathrm{~m}$, the upper $2 \mathrm{~m}$ were considered surface, the bottom $2 \mathrm{~m}$ were recorded as bottom, and samples from intervals between as water column (Figure 2). Our collecting methods were designed to not disturb the natural movements of the tadpoles, and allow for their natural movements to enter our traps set at different depths. So even though we use the terms surface, water column, and bottom, in reality we did not sample the bottom or the surface only the water column at different depths. So categories are actually water column near the bottom, water column, and water column near the surface.

Figure 2 - Criteria for assignment of microhabitat categories as a function of trap depth and water depth (meters). 


\section{Statistical Analysis}

Fluctuations in monthly tadpole abundance for all species were tested for significance with the Kruskal-Wallis test with all species and all months in which tadpoles were collected being considered.

Niche breadth - The microhabitat breadth was calculated following Heyer (1976, 1979), by the formula $\mathrm{B}_{\mathrm{j}}=\sum \mathrm{P}_{\mathrm{ij}}{ }^{2}$, where $\mathrm{B}_{\mathrm{j}}$ is the amplitude of the microhabitat of the species $\mathrm{j}$ and $\mathrm{P}_{\mathrm{ij}}$ the proportion of the species $\mathrm{j}$ which occurs in the microhabitat $i$ (modification of Levins 1968).

Spatial-Temporal Distribution - We used a $\mathrm{G}$ test (Zar 1984), constructing a multi-way contingency table (habitat-time-species) to evaluate the spatial-temporal interaction then calculated bidimentional microhabitat overlap for time, beginning with the index of overlap as follows. Similarity in resource use between two consumers was estimated by Pianka's (1973) niche overlap coefficient: $\varnothing_{\mathrm{jk}}=\sum \mathrm{P}_{\mathrm{ij}} \mathrm{P}_{\mathrm{ik}} / \sqrt{ } \sum$ $\mathrm{P}_{\mathrm{ij}}{ }^{2} \mathrm{P}_{\mathrm{ik}}{ }^{2}$, where $\mathrm{P}_{\mathrm{ij}}$ and $\mathrm{P}_{\mathrm{ik}}$ represent the proportional use of resource state $\mathrm{i}$ by user species $\mathrm{j}$ and species $\mathrm{k}$. This overlap index ranges from zero when no resources are shared to 1.0 for complete identity in resource use between two species (Pianka 1973). These indices were calculated grouping two consecutive months.

Index of electivity - We estimated one index of electivity following Jacobs (1974) calculated for each two-month sample: $e_{i}=\left(p_{i}-q_{i}\right) /\left(p_{i}+\right.$ $\left.q_{i}-2 p_{i} q_{i}\right)$, where $p$ is the proportion of captures in the microhabitat $i$ during one sampling period and $\mathrm{q}$ is the proportion of sampling periods available for microhabitat $i$.

Resource use - We measured resource use by the index g of Winemiller and Pianka (1990), which uses the geometric mean of $\mathrm{p}_{\mathrm{i}}$ and $\mathrm{e}_{\mathrm{i}}\left(\mathrm{g}_{\mathrm{i}}=\right.$ $\left.\sqrt{ } p_{i} e_{i}\right)$. The values ranged from 0 to 1 using the formula $e_{i}{ }^{\prime}=\left(1+e_{i}\right) / 2$. So that the index does not lose its properties, this transformation is made only within the cartesian plane.

Interspecific Covariation - Interspecific covariation was analyzed by Spearman's rank correlation that separated the data by month and by habitat for all months to produce an overview of total covariation.

\section{Results}

Considerable seasonal variation in both the abundance of tadpoles and the diversity of species occurred. We collected tadpoles of the following species in order of decreasing abundance: Smilisca baudinii, Gastrophryne usta, Rana berlandieri, Agalychnis callidryas, Hyla ebraccata and Bufo marinus. Only the first three species were abundant enough for analysis (Table 1). Other species also occur in the Laguna del Zacatal but are either rare or ephemeral (Leptodactylus labialis, see below). Other species breed in Laguna del Zacatal (Gastrophryne elegans, Hyla microcephala underwoodi, H. picta, Leptodactylus melanonotus, Rana vaillanti, Bufo cavifrons, and Hyalinobatrachium fleischmanni (Vogt 1997), but no tadpoles of these species were collected during this study. Differences in the abundance of each species each month were significant ( $\mathrm{p}<0.01$, Kruskal-Wallis test). Higher population densities of tadpoles and species diversity occurred during the summer rainy season (June, July, August, and September, Figures 3 and 4). Smilisca baudinii and Gastrophryne usta were most abundant in June and September, whereas Rana berlandieri was most abundant in July and September.

The species which occupied the lake for the longest time and were found in the greatest number of water depths in general had the highest niche breadth (lower the value higher the niche breadth), even though they had the smallest population densities (Table 2). $R$. berlandieri had the highest microhabitat breadth $\left(\mathrm{B}_{\mathrm{j}}=0.1824\right)$, followed by $S$. baudinii and $G$. 
usta. Niche breadth calculations show that $G$. usta is more of a specialist than $R$. berlandieri in this habitat (Table 2). The extension proposed by Llewellyn and Jenkins (1987) for the bootstrap method described by Mueller and Altenberg (1985) was used to assess the statistical significance of niche breadth differences between species and seasons. By using this method, we found that the niche breadth of $G$. usta was significantly less than that of $S$. baudinii during the two pairs of months in which both species were present
(June-July, p < 0.05; August-September, $\mathrm{p}<$ $0.05)$, and for the entire season ( $<<0.05)$. G. usta and $R$. berlandieri had similar niche breadths, although G. usta was significantly less, during August-September and OctoberNovember. Niche breadths of $S$. baudinii were significantly greater in June-July than in AugustOctober $(\mathrm{p}<0.05)$. Niche breadths of $S$. baudinii were significantly greater in June-July. $R$. berlandieri had a niche breadth significantly different among all months $(\mathrm{p}<0.05$ for all pairs).

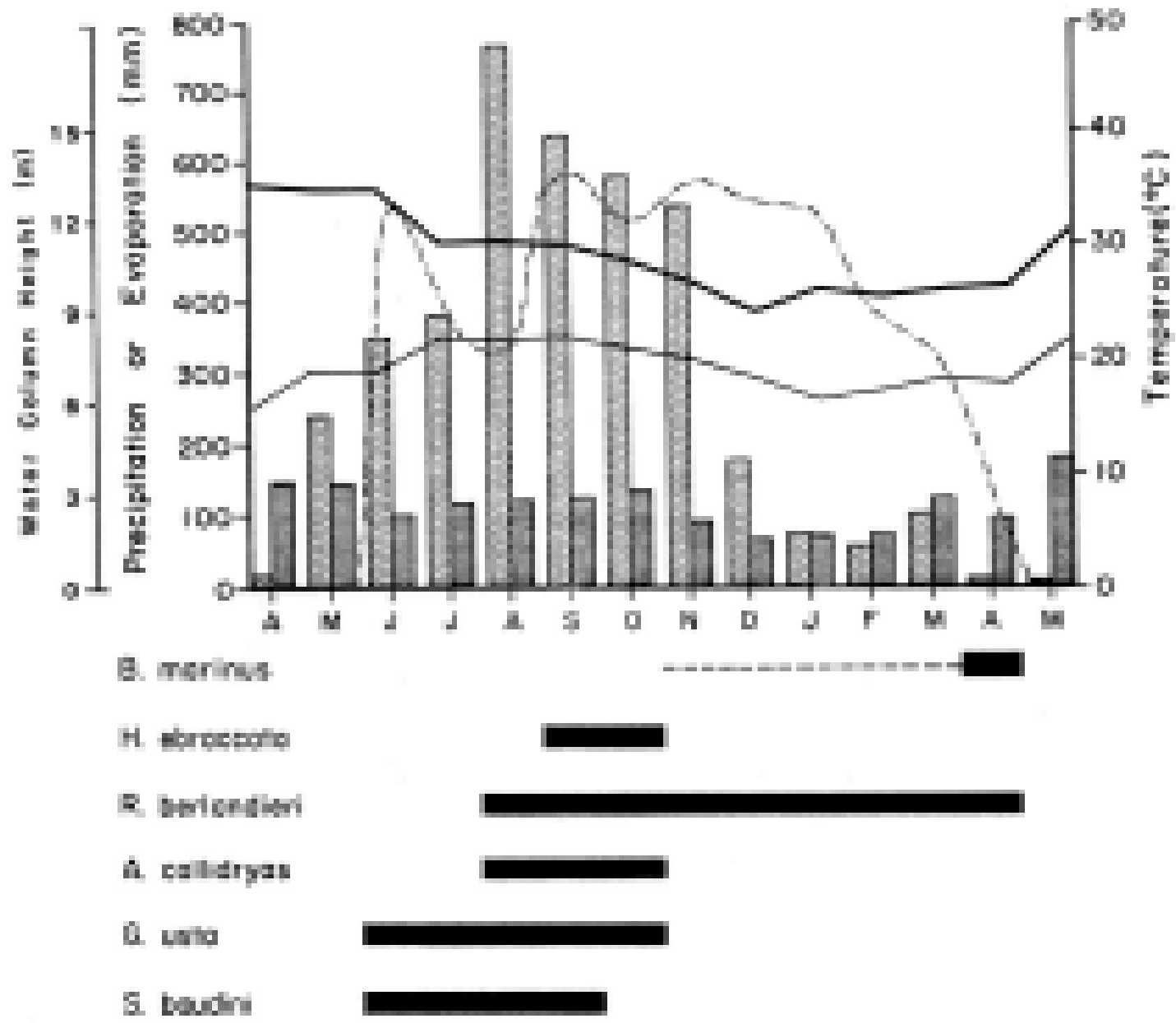

Figure 3 - Temporal occurrence of tadpole species related to monthly mean maximum (heavy line) and minimum (narrow line) temperatures, precipitation (dotted bars) and evaporation (lined bars). The broken line is the water depth of the lake. All data from the study period (1986-1987). 
Time-space interaction correlations were positive (multiway contingency table; $\mathrm{G}=$ 565,368; 72 df; $p<0.001$ ), so we performed overlap analyses. The only overlap was between S. baudinii and Gastrophryne usta (June $\varnothing_{\mathrm{jk}}=$

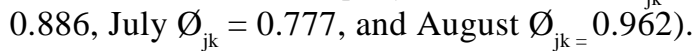
All of the other months and pairs of species had indices of zero, primarily because one or two species was not present in significant numbers.

Temporal partitioning was present between both Rana berlandieri and S. baudinii, and between R. berlandieri and G. usta (Figure 4). For S. baudinii and G. usta, when there was greatest abundance of both species (July) their overlap was lower $\left(\varnothing_{\mathrm{jk}}=0.777\right)$ compared to August $\left(\varnothing_{\mathrm{jk}}=0.962\right)$, supporting Schoener's (1982) prediction of reduced niche overlap between sympatric species during times of scarce resources or high densities. However, this pattern was not found in June $\left(\varnothing_{\mathrm{jk}}=0.886\right)$, when tadpole abundance was greater than in August.

Electivity values are low, indicating no habitat preference. The results of this index have little utility in analysis of resource partitioning because it is very sensitive to the variation in the availability of resources.

S. baudinii and G. usta covary significantly and positively only in the surface microhabitat in June and July and in the surface and water column microhabitats for the entire season (Table 3, Figure 4). June and July are the months of greatest abundance of tadpoles and the surface microhabitat is being used more by these two species in this pair of months (Figure $5)$ than in other months. This means that these two species are similarily influenced by the environment and may partition resources in another way (food partitioning was not analyzed in this study; but surely true, one is a rasper and

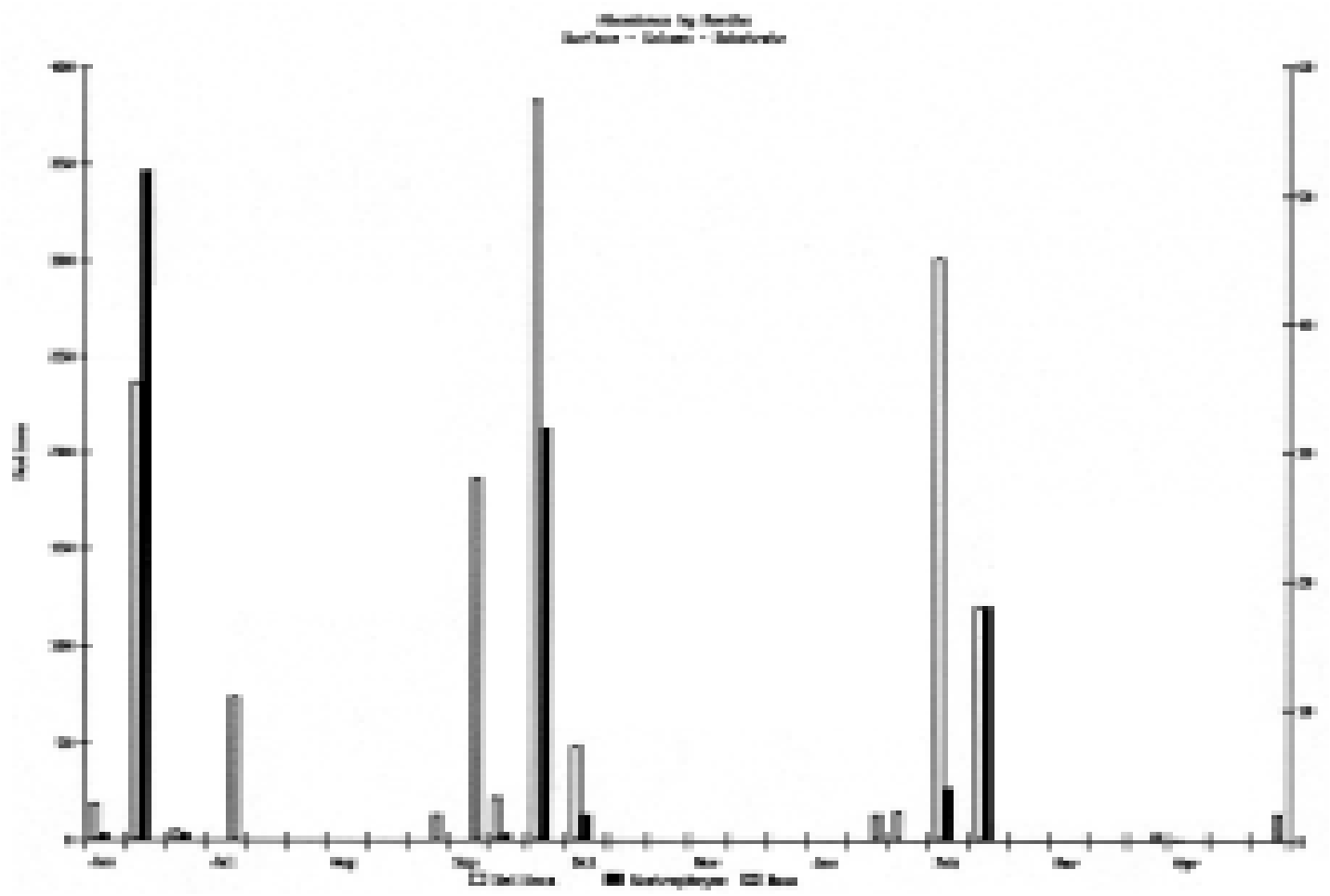

Figure 4 - Monthly median numbers of tadpoles per trap for each microhabitat for each species. 
one is a suspension feeder). There appears to be competition for space with $R$. berlandieri. For both species covariation with $R$. berlandieri was negative. $R$. berlandieri directly affects $S$. baudinii, but affects $G$. usta indirectly or less intensely. This is evident from the observation that the covariation between $R$. berlandieri and $G$. usta is less significant than that for $R$. berlandieri and $S$. baudinii (Table 3 ). The presence of $R$. berlandieri in the surface samples in August-September appears to modify space use (Figure 5) since the other two species are then found in the water column and bottom samples. These data show that resource partitioning between $R$. berlandieri and the other two species takes place in the time dimension.

\section{Discussion}

Tadpole faunas have been studied in various regions, particularly in the neotropics (Heyer et al. 1975, Wild 1996, Eterovick and Sazima 2000, Eterovick and Fernandes 2001, Eterovick and Barros, in press ), Asia (Heyer 1973, Inger et al. 1986), and North America (Heyer 1976, 1979). Communities differ in ecological structure in different regions, water quality and the dimensions of the body of water studied also affect community structure.

In this study the greatest species richness occurred when Laguna de Zacatal was of intermediate size; it was of sufficiently permanence to increase the probability for the tadpoles to complete metamorphosis but not for the population of predators to be so great as to decimate the tadpole community. The pattern of water depth partitioning among the members of the assemblage in this study could be affected by the differences in susceptibility of the tadpoles of different species of anurans to desiccation or predation (Cecil and Just 1979, Heyer et al. 1975, Toft 1985, Wilbur 1980). The structure and dynamics of this tadpole assemblage do not appear to be affected by the desiccation factor, because the lake remains full

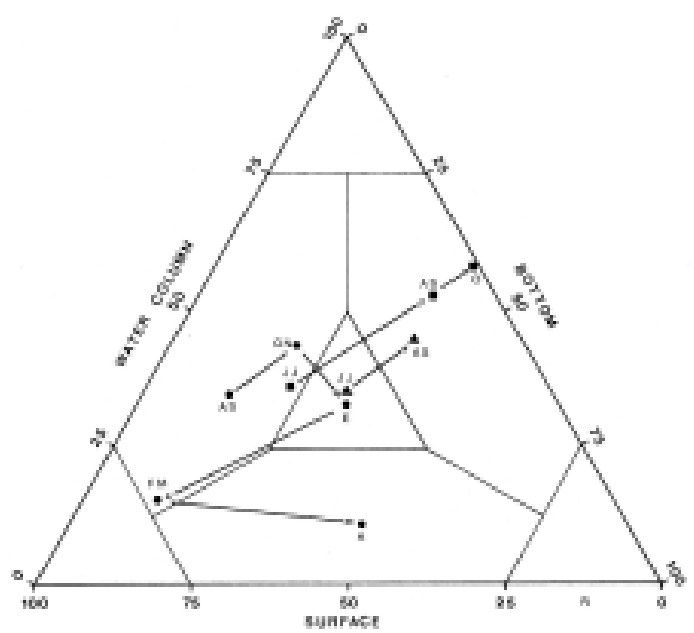

Figure 5 - Graphic representation of the three categories of habitat resources and use by the study species (see text for description). The three species are represented by the following symbols: Gastrophryne usta, square; Rana berlandieri, circle; and Smilisca baudinii, triangle. Symbols for samples are: JJ, JuneJuly; AS, August-September; O, October; ON, October-November; E, January; FM, FebruaryMarch; A, April.

for a much greater period than that required for the metamorphosis of all of the species (Vogt 1997). These observations seem to depend more on the pattern of reproduction of the anurans. Many of the species migrate to the lake for reproduction during summer rains. The tadpole density found in the lake is correlated with the density of breeding adults and the clutch size of each species (Vogt, 1997). Smilisca baudinii breeds in the first part of the rainy season at densities $>10,000$, whereas Rana berlandieri breeds later at lower densities.

Temporal and habitat partitioning occurs in this assemblage of tadpoles. The phenology of reproduction relates to the temporal dimension while the spatial dimension depends on interactions of the tadpoles with their environment and other organisms. A dynamic interaction occurs between habitat and temporal dimensions. There exists a time of 
Torres-Orozco et al.

Table 1 - Summary of mean numbers of tadpoles collected in each trap in each microhabitat (only the sampling periods when at least one organism was collected).

Table 2 - Amplitude of the microhabitat $\left(\mathrm{B}_{\mathrm{j}}\right)$ and index of use of resources $\left(\mathrm{g}_{\mathrm{i}}\right)$ for three tadpole species from Laguna del Zacatal, Mexico. The values range from 0 to 1 . Both indices were calculated for each two month period and for the entire study period. S, surface; C, water column; B, bottom; SA, species absent. 
Neotropical tadpoles: spatial and temporal distribution and habitat use in a seasonal lake in Veracruz, México

Table 3 - Coefficients of Spearman's rank correlation for species pairs based on the number of organisms per trap (for traps containing at least one organism). The data were partitioned in the following manner: (a) in time, for pairs of months (data from December through April were not used because the only species present was Rana berlandieri); (b) in space, for each microhabitat (surface, water column and bottom); (c) in time and space, for every two month period and each microhabitat; and (d) a total, for all months and all microhabitats. *** $\mathrm{p}<0.001$; ** $\mathrm{p}<0.01$; ${ }^{*} \mathrm{p}<0.05$; ns, not significant; SA, at least one of the two species was absent.

cohabitation among the three mentioned species. Partitioning of resources occurs between $R$. berlandieri and the other two species in the time dimension and between S. baudini and G. usta probably in the food dimension.

There exists a time of cohabitation among the three species mentioned. Partitioning of resources occurs between $R$. berlandieri and the other two species in the time dimension and between $S$. baudinii and G. usta probably in the food dimension. But when the three species are present for spatial-temporal interaction the 
habitat is partitioned (at least at the microhabitat level), what may be a response to competition. There may be high-order interactions, as $R$. berlandieri affects both $S$. baudinii and G. usta. The predictions of Morse (1974) explain this phenomenon. This could be because the species, which have co-occurred through time have evolved segregation, but when they overlap in time with other species then the competitive interaction becomes stronger.

Also, the phenology of the lake is important in these interactions. The change in availability of water depths through time determines the pattern of spatial dimensions. The spatial dimension (the availability of depths) plays a fundamental role. Through time the reduction in depth and water volume results in an increased density of organisms. The persistence of the lake permits the establishment of predators (fish swim upstream and enter Laguna Zacatal after it overflows and into an intermittent stream connecting the $2 \mathrm{~km}$ distance to Laguna Escondida) and they can reduce tadpole populations to lower densities toward the end of the season. A combination of the filling and drying cycle and climatic conditions could have influenced the reproductive phenology of the different species. The low initial tadpole densities could be related to low water levels in the laguna and also to the presence of Leptodactylus labialis. This species lays its eggs in foam nests on the dry floor of the laguna during the dry season, and at the start of the rainy season they are the first tadpoles present while the laguna is filling. They are predators of eggs and recently emerged tadpoles of other species (Vogt 1997).

We observed the following processes in the temporal-habitat dimensional interaction. The phenology of each species and the hierarchical process of habitat selection depend both on the species involved as well as abiotic and biotic environmental factors. Ontogenetic effects were not considered in this study. Although densities were not high for the majority of species, the absence of permanent aquatic predators, the size of the laguna, and the favorable climate of the region influence distinct short-term patterns in resource partitioning within this assemblage. However they do not alter long-term population dynamics or community structure.

\section{Acknowledgements}

J. L. Buen Abad and B. Cerda are thanked for their enthusiastic collaboration with the collecting. The personnel of the Estacion de Biologia Tropical "Los Tuxtlas" particularly the former station director, Rodolfo Dirzo, are thanked for making the facilities of the station available for use. J. L. Garcia-Calderon, A. Ortega and J. J. Schmitter helped with the initial manuscript preparation. C. J. McCoy and William Mathews are thanked for reviewing an earlier version of the manuscript. Tici for scanning the final version of the lost manuscript. Special thanks to Paula Cabral Eterovick for reviewing this well aged $\mathrm{ms}$ and bringing it up out of the dark ages to include present day literature including a paper she has in press.

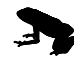

\section{References}

Cecil, S. G. and J. J. Just. 1979. Survival rate, population density and development of a naturally occurring anuran larvae (Rana catesbeiana). Copeia 1979: 447453.

Eterovick, P. C. and I. Sazima. 2000. Structure of an anuran community in a montane meadow in southeastern Brazil: effects of seasonality, habitat, and predation. Amphibia-Reptila 21: 439-461

Eterovick, P. C. and G. W. Fernandes. 2001. Tadpole distribution within montane meadow streams at the Serra do Cipó, southeastern Brazil: ecological or phylogenetic constraints? Journal of Tropical Ecology 17: $683-693$

Eterovick, P. C. and I. S. Barros. Niche occupancy in southeastern Brazilian tadpole communities in montane-meadow streams. Journal of Tropical Ecology. (in press.)

Gascon, C. 1991. Population- and community- level analyses of species occurrences of central Amazonian Rainforest tadpoles. Ecology 72: 1731-1746. 
Heyer, W. R. 1973. Ecological interactions of frog larvae at a seasonal tropical location in Thailand. Journal of Herpetology 7: 337-361.

Heyer, W. R. 1976. Studies in larval amphibian habitat partitioning. Smithsonian Contributions to Zoology 242: $1-27$.

Heyer, W. R. 1979. Annual variation in larval amphibian populations within a temperate pond. Journal of the Washington Academy of Sciences 69: 65-74.

Heyer, W. R., R. W. McDiarmid, and D. L. Weigmann. 1975. Tadpoles, predation and pond habitats in the tropics. Biotropica 7: 100-111.

Inger, R. F., H. K. Voris, and K. J. Frogner. 1986. Organization of a community of tadpoles in rain forest streams in Borneo. Journal of Tropical Ecology 2: 193-205.

Jacobs, J. 1974. Quantitative measurement of food selection: a modification of the forage ratio and Ivlev's electivity index. Oecologia (Berlin) 14: 413-417.

Levins, R. 1968. Evolution in Changing Environments: Some Theoretical Explorations. Princeton. Princeton University Press. 120 pp.

Llewellyn, J. B. and S. H. Jenkins. 1987. Patterns of niche shift in mice: seasonal changes in microhabitat breadth and overlap. American Naturalist 129: 365-381.

Miller, R. S. 1967. Pattern and process in competition. Advances in Ecological Research 4: 1-74.

Morin, P. J. 1983. Predation, competition, and the composition of larval anuran guilds. Ecological Monographs 53: 119-138.

Morse, D. H. 1974. Niche breadth as a function of social dominance. American Naturalist 108: 818-830.

Mueller, L. D. and L. Altenberg. 1985. Statistical inference on measures of niche overlap. Ecology 66: 1204-1210.
Pianka, E. R. 1973. The structure of lizard communities. Annual Review of Ecology and Systematics 4: 53-74.

Pianka, E. R. 1975. Niche relations of desert lizards. Pp. 292-314 in M. L. Cody and J. M. Diamond (eds.), Ecology and Evolution of Communities. Harvard University Press.

Schoener, T. W. 1986. Mechanistic approaches to community ecology: a new reductionism? American Zoologist 26: 81-106.

Steinwascher, K. 1979. Competitive interactions among tadpoles: responses to resource level. Ecology 60: 1172-1183.

Toft, C. A. 1985. Resource partitioning in amphibians and reptiles. Copeia 1985: 1-21.

Torres-Orozco, R. E., C. R. Jiménez-Sierra, J. L. B. Abad, and A. Pérez-Rojas. 1997. Limnologia. Pp. 33-41 in E. González Soriano, R. Dirzo, and R. C. Vogt (eds.), Historia Natural de Los Tuxtlas. UNAM, Mexico D. F..

Vogt, R. C. 1997. Las ranas de Laguna del Zacatal. Pp 500503 in E. González Soriano, R. Dirzo and R. C. Vogt (eds.), Historia Natural de Los Tuxtlas. UNAM, Mexico D. F..

Wilbur, H. M. 1980. Complex life cycles. Annual Review of Ecology and Systematics 11: 67-93.

Wild, E. R. 1996. Natural history and resource use of four Amazonian tadpole assemblages. Occasional Papers of the Museum of Natural History of the University of Kansas 176: 1-59

Winemiller, K. O. and E. R. Pianka. 1990. Organization in natural assemblages of desert lizards and tropical fishes. Ecological Monographs 60: 27-55.

Zar, G. 1984. Biostatistical Analysis. 2nd Edition. New Jersey, Prentice-Hall. $718+$ xiv pp. 